\title{
Food reformulation and nutritional quality of food consumption: an analysis based on households panel data in France
}

\author{
Marine Spiteri ${ }^{1} \cdot$ Louis-Georges Soler ${ }^{2}$
}

Received: 10 May 2017 / Revised: 12 September 2017 / Accepted: 8 October 2017 / Published online: 22 December 2017

(c) The Author(s) 2018. This article is published with open access

\begin{abstract}
Background/objectives We aimed to quantify the contribution of food reformulation to changes in the nutritional quality of consumers' food purchases, and compare it with the impact of substitutions made by consumers.

Subjects/methods Using a brand-specific data set in France, we considered the changes in the nutrient content of food products in four food sectors over a 3-year period. These data were matched with data on consumers' purchases to estimate the change in the nutritional quality of consumers' purchases. This change was divided into three components: the reformulation of food products, the launching of new products and the consumers' substitutions between products. Key nutrients were selected for each food group: breakfast cereals (sugar, fats, SFA, fiber, and sodium), biscuits and cakes (sugar, fats, SFA, and fiber), potato chips (fats, SFA, and sodium) and soft drinks (sugar).

Results Product reformulation initiatives have improved existing products for most food group-nutrient pairs. In particular, the contribution of food reformulation to the change in nutritional quality of food purchases was strong in potato chips (the sales-weighted mean SFA and sodium contents decreased by $31.4 \%$ to $52.1 \%$ and $6.7 \%$ to $11.1 \%$, respectively), and breakfast cereals (the sales-weighted mean sodium content decreased by $7.3 \%$ to $9.7 \%$ ). Regarding the launching of new products, the results were ambiguous. Consumers' substitutions between food items were not generally associated to an improvement in the nutritional quality of the food purchases.
\end{abstract}

Conclusions Policies aiming to promote food reformulation may have greater impact than those promoting changes in consumer behavior.

\section{Introduction}

To promote healthier diets, two types of interventions are generally considered. The first one aims at increasing consumers' awareness of the relationship between food and health, through information and education campaigns. Prior literature shows that these policies have positive albeit small effects. The second type of intervention aims at improving the food environment of consumers [1,2] in order facilitate healthy choices. The reformulation of food products, through the decrease in salt, fat or sugar contents, is an

Louis-Georges Soler

louis-georges.soler@inra.fr

1 Toulouse School of Economics, INRA, University of Toulouse Capitole, Toulouse, France

2 INRA-Aliss UR 1303, 65 Boulevard de Brandebourg, 94205 Ivry sur Seine, France example of this type of intervention made to favor a better food environment [3-8]. In many countries, public health agencies implement partnerships with the food industry and the retail sector in order to improve the nutritional quality of foods available on the market [9-13].

What can we expect from such policies focusing on the supply side? The potential impact of food reformulation initiatives on consumers' intakes and public health has been investigated in recent studies. Based on simulations, reformulation scenarios related to salt [14-18] or trans fats [19] contents in foods, or based on the adoption of quality standards by the food industry [20-25], show that the modification of the nutritional quality of foods may potentially induce significant health benefits.

However, considering the available literature, it is worthwhile to note that most articles address the effects of "potential" changes in food quality and are based on reformulation scenarios and simulations rather than "real" changes implemented by the food industry. The reason that most 
articles address potential reformulation scenarios is linked to the lack of precise data on quality changes and reformulation initiatives implemented by the food industry [26, 27]. Recently, however, such data sets have been developed in some countries [28-30], enabling researchers to evaluate not only "potential" scenarios of food reformulation but also real changes implemented by the food industry.

Based on data collected in France, the aim of this article is to contribute to estimating the magnitude of reformulation efforts implemented by the food industry and quantifying their impact on the nutritional quality of consumer purchases.

\section{Methods and data}

The changes in consumers' nutrient intakes between two dates may result from changes in consumption patterns (consumer purchases switch from some products to others) or changes in the quality of the food products available on the market. These changes on the supply side can be caused by the launching of new products and the removal of old products or the reformulation (i.e., the change in the nutritional composition) of already existing products. In order to analyze the changes in salt intakes in the U.K., a recent article [28] proposed a method to quantify these three effects. Longitudinal data on the contents of the grocery baskets of a nationally representative sample of households showed that the average salt content of grocery purchases fell by $5.1 \%$, from $0.370 \mathrm{~g}$ in 2005 to $0.351 \mathrm{~g}$ in 2011 . This variation was divided into three components: reformulation of existing food products by manufacturers, the net effect of the launching/removal of products, and consumer switching between products. We applied a similar method in France by focusing on four specific food groups and considering a larger set of key nutrients.

\section{A focus on four food sectors}

Four food groups were considered (breakfast cereals, biscuits and cakes, potato chips, and soft drinks) for two reasons. First, these food groups are strong contributors to the intake of some nutrients that the French public health agency recommends limiting (See https://www.anses.fr/fr/content/1\% E2\%80\%99anses-actualise-les-rep\%C3\%A8res-deconsommations-alimentaires-pour-la-population-fran $\% \mathrm{C} 3 \%$ A7aise). Second, voluntary commitments to food reformulation have been taken by several companies involved in these sectors (See http://solidarites-sante.gouv.fr/preventionen-sante/preserver-sa-sante/le-programme-national-nutritionsante/article/les-signataires-des-chartes-d-engagements-deprogres-nutritionnels and http://agriculture.gouv.fr/alimenta tion/accords-collectifs-pour-lamelioration-de-loffre-alimenta ire). Data on the nutritional content of food products were obtained from the French Food Quality Observatory (See www.oqali.fr/oqali_eng/) (Oqali). The Oqali database is brand-specific and is specifically designed to follow, over time, the changes in the nutrient contents of products sold on the French market. Depending on the food groups, data were first collected between 2008 and 2010, and the same protocol was repeated in 2011 or 2013 so that the observation period covered two or 3 years. Key nutrients were selected for each food category: sugar, fats, saturated fats (SFA), fiber, and sodium for breakfast cereals; sugar, fats, saturated fats, and fiber for biscuits and cakes; fats, saturated fats, and sodium for potato chips; and sugar for soft drinks. Table 1 displays the number of products considered in each food category, the covered market shares and the initial and second dates of data collection. Within each food category, the sampled food products were partitioned into three subgroups: products removed from the market between $t_{0}$ and $t_{1}$ (Group X), paired products present on the market at both $t_{0}$ and $t_{1}$ (Group C), and new products launched before $t_{1}$ (Group N). Food composition data were matched with purchase data from Kantar Worldpanel (The Kantar Worldpanel database provides details on the quantities bought and the corresponding food expenditures by a representative panel of 20,000 households in France) to compute the market share of each product at dates $t_{0}$ and $t_{1}$ (The use of nutritional data was approved by the steering committee of Oqali. We did not have to ask for an ethical agreement as the food purchase data were anonymous).

\section{Decomposing the contributions of the food industry and consumer behavior changes}

To measure the evolution of the nutritional quality of food purchases, we considered the changes in the sales-weighted average content of key nutrients between dates $t_{0}$ and $t_{1}$ in each food group. To disentangle the effects of changes on the supply side from those on the consumer side, we used the method proposed by Griffith et al. [28]. Let us denote $S_{\mathrm{t}}$ as the sales-weighted mean content of a specific key nutrient for one food group at time $t$. This value is given at $t_{0}$ and $t_{1}$ by

$$
\begin{aligned}
& S_{\mathrm{t}_{0}}=\sum_{i} w_{i t_{0}} s_{i t_{0}} \\
& S_{\mathrm{t}_{1}}=\sum_{i} w_{i t_{1}} s_{i t_{1}}
\end{aligned}
$$

where $i$ indexes individual food products, $w_{i t_{0}}$ is the market share of the food product $i$ at $t_{0}$, and $s_{i t_{0}}$ denotes the content of a given nutrient of the food product $i$ at $t_{0}$ (similar notation applies for $t_{1}$ ). The change in the sales-weighted mean content of a specific key nutrient between $t_{0}$ and $t_{1}$ is defined as $\Delta S=S_{t_{1}}-S_{t_{0}}$. The decomposition into supply 
and demand effects is given by

$$
\begin{aligned}
& \Delta S=\sum_{i \in C} w_{i t_{0}}\left(s_{i t_{1}}-s_{i t_{0}}\right) \\
& +\sum_{i \in N} w_{i t_{1}}\left(s_{i t_{1}}-S_{t_{o}}\right)-\sum_{i \in X} w_{i t_{0}}\left(s_{i t_{0}}-S_{t_{0}}\right) \\
& +\sum_{i \in C}\left(s_{i t_{0}}-S_{t_{0}}\right)\left(w_{i t_{1}}-w_{i t_{0}}\right)+\sum_{i \in C}\left(s_{i t_{1}}-s_{i t_{0}}\right)\left(w_{i t_{1}}-w_{i t_{0}}\right)
\end{aligned}
$$

In this expression, the first term (1) accounts for the effect of food reformulation carried out on products collected at both $t_{0}$ and $t_{1}$ considering their market share at $t_{0}$. Thus, the contribution of a reformulated product to this term will be greater if its market share at $t_{0}$ is high. The second term (2) captures the impact of product renewal, more precisely, the entry of products to the market or their withdrawal between $t_{0}$ and $t_{1}$. This term takes into account the nutrient content of the new products or the removed products (compared with the overall sales-weighted mean nutrient content at $t_{0}$ ) and their market shares. Thus, for example, a new product with high sugar content will increase the sales-weighted mean sugar content of the food group. This effect will be more important if its market share is high. The last term (3) reflects consumer switching inside group $\mathrm{C}$ (products collected at both $t_{0}$ and $t_{1}$ ):

- The sub-term $\sum\left(s_{i t_{0}}-S_{t_{0}}\right)\left(w_{i t_{1}}-w_{i t_{0}}\right)$ represents the contribution $i \in C$ of a change in the market share of a product between $t_{0}$ and $t_{1}$. For example, if consumers shift toward products that have high sugar content (compared with the sales-weighted mean sugar content of the food group at $t_{0}$ ), this step will raise the overall sales-weighted mean sugar content.

- The sub-term $\sum\left(s_{i t_{1}}-s_{i t_{0}}\right)\left(w_{i t_{1}}-w_{i t_{0}}\right)$ captures the cross effect of ${ }^{i \in C}$ changes in the nutrient content and in the market shares of group $\mathrm{C}$ products. For example, if consumers shift towards products that are reformulated to have less sugar, this term will be negative.

\section{Data processing}

The algorithm presented above is valid if the total market shares covered at $t_{0}$ and $t_{1}$ are equal to $100 \%$ and the nutritional composition of the sampled products is known. This scenario is not exactly the case, as the Oqali samples do not cover $100 \%$ of the sales volume. Two scenarios of data processing, based on different assumptions, were considered. A first computation (scenario 1) was modeled by assuming that the non-collected references had, on average, the same characteristics as the whole sample and followed the same evolution between $t_{0}$ and $t_{1}$. This data processing distorts the data less if the market coverage of the samples studied is high and of the same order of magnitude at $t_{0}$ and $t_{1}$, and if the samples are representative of the market at each time of data collection. A second computation (scenario 2) was modeled by assuming that the products that were not identified in the Oqali data set but were present in the Kantar Worldpanel data set had, on average, the same nutritional composition as the whole sample and were stable over the period of observation. Finally, missing nutrient composition data were inferred by assuming that the products had not been reformulated.

\section{Results}

Figure 1 displays the proportion of the three types of products (X, C, and $\mathrm{N}$ ) in each food group by applying scenario 1. Around a quarter of the market was renewed during the observation period. Tables 2 to 5 present the effects of food reformulation, product renewal and consumer switching. As expected, both scenarios led to similar results, but the magnitude was lower with scenario 2, which tends to overestimate the volumes of the group $\mathrm{C}$ products and underestimate the magnitude of reformulation initiatives. In the following sections, the estimated effects of food reformulation, product renewal and change in consumer choice will be discussed as a range of results, with the low range corresponding to the results obtained with scenario 2 and the high range corresponding to those obtained with scenario 1.

\section{Breakfast cereals}

In the breakfast cereal sector, one can observe strong changes in the sales-weighted average contents of fats and saturated fats $(+7.5$ to $10.1 \%$ and +10.2 to $13.6 \%$, respectively). Evidently, it is consumer choices that mostly

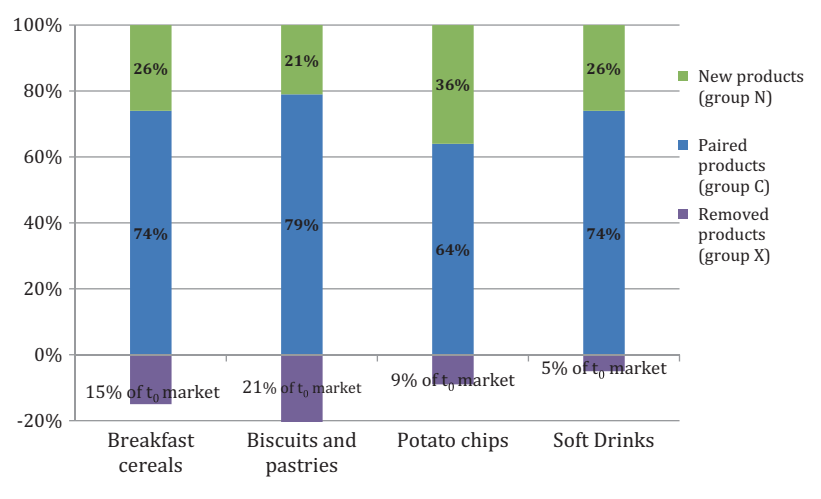

Fig. 1 Partitioning of the samples into subgroups (in market shares) 
Table 1 Characteristics of the samples of food products

\begin{tabular}{llllllll}
\hline & Date $t_{0}$ & & & Date $t_{1}$ & \\
\cline { 2 - 3 } & Year & Number of products & Covered market share (\%) & & Year & Number of products & Covered market share (\%) \\
\hline Breakfast cereals & 2008 & 254 & 75.1 & 2011 & 362 & 74.6 \\
Biscuits and cakes & 2008 & 1436 & 70.4 & 2011 & 1824 & 65.4 \\
Potato chips & 2009 & 135 & 60.4 & 2011 & 217 & 81 \\
Soft drinks & 2010 & 619 & 78.1 & 2013 & 1208 & 86.3 \\
\hline
\end{tabular}

explain the negative change, from a public health point of view, of the weighted average contents of these nutrients.

One can also observe an interesting decrease in the salesweighted average sodium content in breakfast cereals $(-8.3$ to $-11.1 \%$ ). This decrease is clearly the result of reformulations that generated a 7.3 to $9.7 \%$ decrease in the related mean sodium content, and to a lesser degree, consumer switching (generated a 3.6 to $4.9 \%$ decrease). Conversely, the innovation/withdrawal effect partly offsets these improvements, leading to a 2.6 to $3.5 \%$ increase in the sales-weighted mean sodium content.

Finally, it appears that the sales-weighted average sugar content slightly increased in breakfast cereals between $t_{0}$ and $t_{1}(+0.5$ to $0.7 \%)$. Despite some food reformulations that led to decreases in the sales-weighted mean sugar content by 2.3 to $3.0 \%$, consumer switching and product renewal resulted in an increase in the sales-weighted sugar content.

\section{Biscuits and cakes}

Overall, in the biscuits and cakes sector, the changes in the nutritional quality of food purchases between $t_{0}$ and $t_{1}$ were small, except for SFA (the sales-weighted mean SFA content decreased by 2.4 to $3.7 \%$ ).

Food reformulation and, to a lesser extent, consumer switching contributed to decreasing the weighted mean SFA content (by -1.9 to $-2.7 \%$ and by -1.2 to $-2.0 \%$, respectively). However, these improvements were partially offset by product renewal, which led to an increase in the related mean content of 0.7 to $1.0 \%$.

\section{Potato chips}

In the potato chip sector, we observed very strong changes in the sales-weighted average nutrient content in two cases: sodium (the related mean content decreased by 10.2 to $12.6 \%$ ) and SFA (the related mean content decreased by 47.4 to $58.5 \%$ ). In both cases, these changes were mainly due to the reformulation effect and, to a lesser degree (approximately half the size), to the innovation/withdrawal effect. Conversely, consumer switching weakened these changes as they slightly increased the sales-weighted mean contents of SFA (by 1.8 to $16 \%$ ) and sodium (by $2.7 \%$ with scenario 1). This difference is mainly explained by consumers turning away from products that were reformulated to have less SFA and sodium. However, according to the innovation/withdrawal effect, it is worth noting that the consumers switched toward new products with less sodium and SFA.

\section{Soft drinks}

Finally, in the soft drink sector, it appears that the salesweighted average sugar content slightly decreased between $t_{0}$ and $t_{1}$. This decrease was clearly the result of the reformulation effect that generated a 1.7 to $2.2 \%$ decrease and the innovation/withdrawal effect that generated a 2.2 to $2.4 \%$ decrease in the weighted mean sugar content. Conversely, consumer switching offset these effects, leading to a 3.8 to $4.4 \%$ increase in the sales-weighted mean sugar content.

\section{Discussion}

In this study, we aimed to quantify the contribution of food reformulation to changes in the nutritional quality of consumer food purchases. We compared the contribution of food reformulation to that of other factors affecting: the renewal of products on the market and substitutions made by consumers among existing products.

This study clearly has some limitations. The most important one is linked to the non exhaustive coverage of the products available on the market in the Oqali data set. The algorithm used to decompose the variation of the nutritional quality of food purchases into the three effects presented above, imposed to have a full coverage of the market at $t_{0}$ and $t_{1}$. As it was not the case in our data set, we had to make some assumptions about the nutritional content of non-collected items. Two scenarios were considered. Even if the magnitude of the effects differs depending on the scenario, the results seem robust as the general conclusions are the same in both cases.

Overall, the results show that, in the four food groups, product reformulation initiatives implemented by the food 


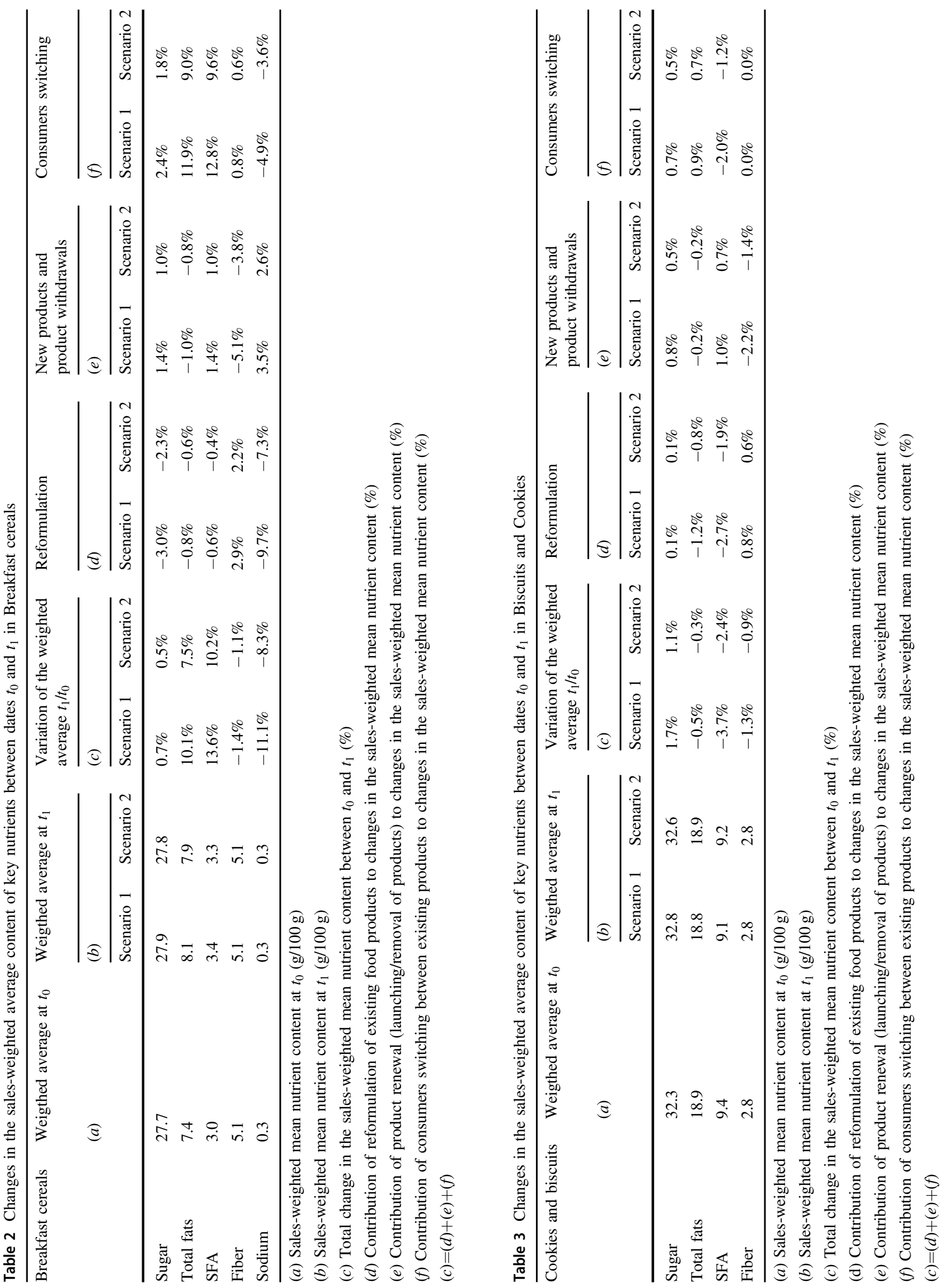




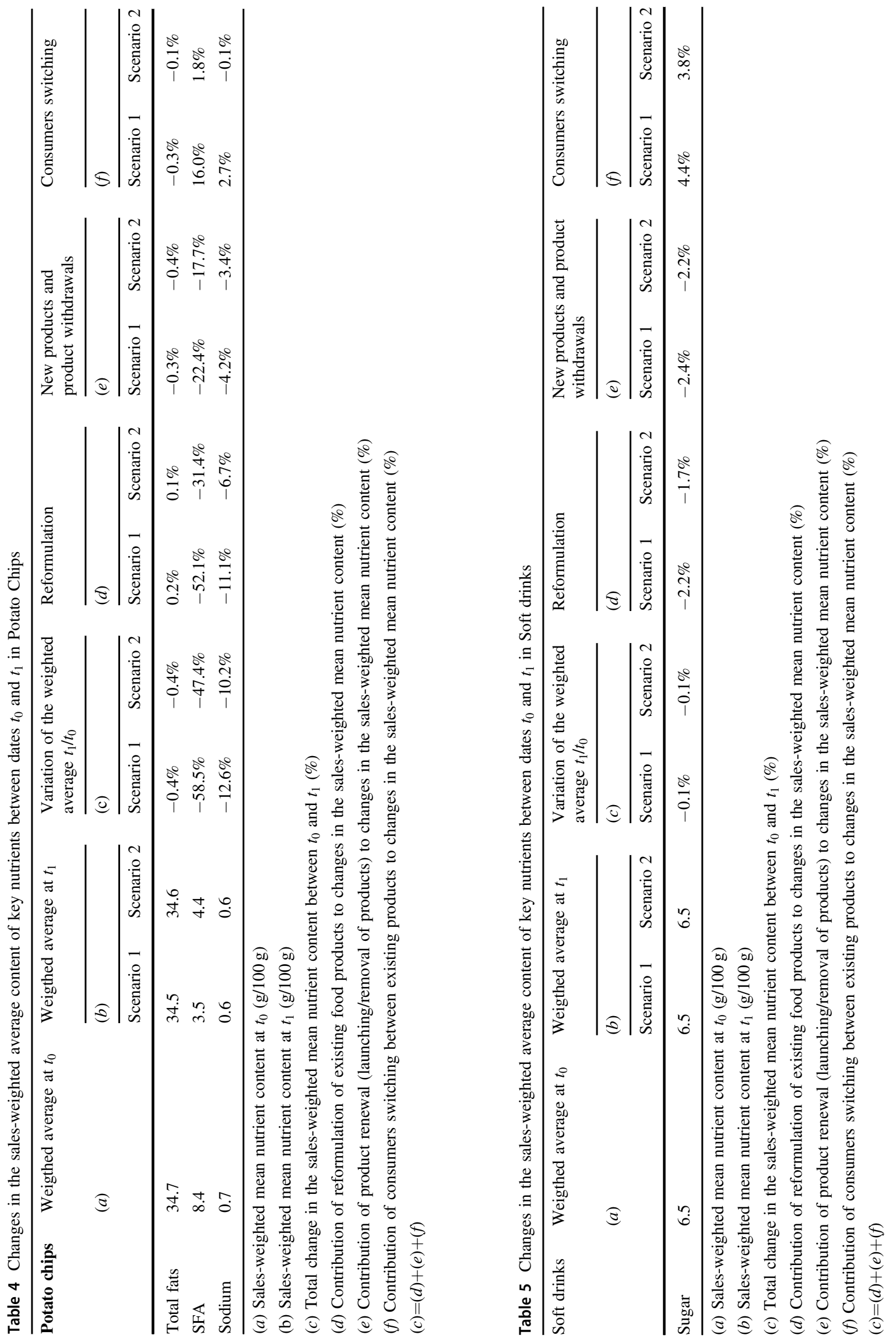


industry have improved existing products (available on the market at $t_{0}$ and $t_{1}$ ) for most targeted food group-nutrient pairs (except for the sugar content of biscuits and cakes and the total fat content of chips). It is likely that some of these changes are linked to individual or collective agreements implemented by the food industry and the French government since 2008. In the breakfast cereal sector, for instance, several agreements were signed between 2008 and 2011, in which two large food manufacturers and several retailers were involved. Another example is given by the potato chips sector. The saturated fat levels in potato chips sharply declined between 2009 and 2011, mainly thanks to reformulations (which led to a -2.6 to $-4.4 \mathrm{~g} / 100 \mathrm{~g}$ decrease in the sales-weighted average content of saturated fats in this sector). This decrease was the result of a collective selfaction by the industry to replace the palm oil used for frying chips with sunflower oil, which contains less saturated fat. In some cases, the magnitudes of the observed changes seem to be modest, but it is important to keep in mind that the period of observation was only 3 years.

Considering now the second effect related to the renewal of the food supply, the results are more ambiguous. Indeed, the launching of new products and the removal of existing ones did not necessarily contribute to the improvement in the nutritional quality of food purchases.

In the soft drink and potato chip sectors, the launching of new products contributed to reducing the sales-weighted mean content of "negative" nutrients. This effect contributed to decreasing the sales-weighted mean sugar content in the soft drink sector by $2 \%$ and the sales-weighted mean SFA content in the potato chips sector by 18 to $22 \%$. However, in the breakfast cereal and biscuits and cakes sectors, it turns out that the renewal of the food supply contributed negatively to achieving public health goals. Indeed, new products with high market shares belonged to categories with poorer nutritional quality compared to the sector average (and vice versa for product withdrawal). The consequence is that, over the observation period, this effect contributed, for instance, to increases of approximately $3 \%$ in the sales-weighted mean sodium content in breakfast cereals and to decreases of approximately $2 \%$ in the salesweighted mean fiber content in biscuits and cakes.

How to explain why supply renewal does not systematically improve the nutritional quality of food purchases? If we assume that consumers do not generally demand products with less salt or less fat and prioritize taste over health [31], then it is understandable that food reformulation initiatives are primarily made to improve the nutritional quality of products already adopted by consumers, provided that the changes in the nutrient content do not affect the product taste (and then they remain small), and they are silently implemented so as not to cause product rejection by consumers. Rather, commercial and communication strategies associated with the launching of new products aim to attract new consumers by promoting taste and pleasure rather than health. Then, integrating more stringent nutritional constraints into the design of new products may be considered "too risky" in some food sectors.

The third effect induced by consumer switching from some products to others did not generally lead to an improvement in the nutritional quality of food purchases during the observation period. In several cases, consumer switching offset the reformulation effect. For instance, in the breakfast cereal sector, it was mainly the consumer switching that explained the negative trend (from a public health point of view) in the weighted average contents of total fat and SFA. It is worth noting that our analysis does not provide any insights to explain consumer changes. They may have changed because they perceived some alteration in taste after product reformulation, or they may have moved for other exogenous reasons (food prices, economic crisis, advertising, etc.).

\section{Conclusion}

Our results converge with other studies [28] that suggest that policies targeting changes in the food supply may have greater impact than those promoting changes in consumer behavior. However, we have shown the complexity of the food reformulation issue, as food companies may act differently depending on the nutrient and food category.

These findings argue for the development of a proper strategy for monitoring the nutrient composition of foods at the brand level in order to evaluate the impact of food reformulation initiatives more precisely $[26,29,30]$.

Acknowledgements We want to thank the steering committee of Oqali for providing the data used in the article. They also thank Florence Stevenin and Oualid Hamza for their contributions to the matching of the data sets and preliminary treatments. Both authors are responsible for the design and implementation of the study, as well as the writing and final content of the article. This research was funded by the EU Horizon 2020 Program under Grant Agreement no. 633692 (SUSFANS).

\section{Compliance with ethical standards}

Conflict of interest The authors declare that they have no competing interests.

Open Access This article is licensed under a Creative Commons Attribution-NonCommercial-NoDerivatives 4.0 International License, which permits any non-commercial use, sharing, distribution and reproduction in any medium or format, as long as you give appropriate credit to the original author(s) and the source, and provide a link to the Creative Commons license. You do not have permission under this license to share adapted material derived from this article or parts of it. The images or other third party material in this article are included in the article's Creative Commons license, unless indicated otherwise in a 
credit line to the material. If material is not included in the article's Creative Commons license and your intended use is not permitted by statutory regulation or exceeds the permitted use, you will need to obtain permission directly from the copyright holder. To view a copy of this license, visit http://creativecommons.org/licenses/by-nc-nd/4.0/.

\section{References}

1. Brambila-Macias J, Shankar B, Capacci S, Mazzocchi M, PerezCueto FJA, Verbeke W, et al. Policy interventions to promote healthy eating: A review of what works, what does not, and what is promising. Food Nutr Bull. 2011;32:365-75.

2. Capacci S, Mazzocchi M, Shankar B, Macias JB, Verbeke W, Perez-Cueto FJA, et al. Policies to promote healthy eating in Europe: a structured review of policies and their effectiveness. Nutr Rev. 2012;70:188-200.

3. Gillespie DO, Allen K, Guzman-Castillo M, Bandosz P, Moreira $\mathrm{P}, \mathrm{McGill} \mathrm{R}$, et al. The health equity and effectiveness of policy options to reduce dietary salt intake in England: Policy Forecast. PLoS ONE. 2015;10:e0127927.

4. Knai C, Petticrew M, Durand MA, Eastmure E, James L, Mehrotra A, et al. Has a public-private partnership resulted in action on healthier diets in England? An analysis of the public health responsibility deal food pledges. Food Policy. 2015;54:1-10.

5. L'Abbe MR, Stender S, Skeaff M, Ghafoorunissa, Tavella M. Approaches to removing trans fats from the food supply in industrialized and developing countries. Eur J Clin Nutr. 2009;63: S50-67.

6. Reeve B, Magnusson R. Food reformulation and the (neo)-liberal state: new strategies for strengthening voluntary salt reduction programs in the UK and USA. Public Health. 2015;129:1061-73. (Reprinted from Public Health, Vol. 129, pg 351-363, 2015)

7. Requillart V, Soler LG. Is the reduction of chronic diseases related to food consumption in the hands of the food industry? Eur Rev Agric Econ. 2014;41:375-403.

8. Eyles H, Webster J, Jebb S, Capelin C, Neal B, Mhurchu CN. Impact of the UK voluntary sodium reduction targets on the sodium content of processed foods from 2006 to 2011: Analysis of household consumer panel data. Prev Med. 2013;57:555-60.

9. Chauliac M, Hercberg S. Changing the food environment: The French experience. Adv Nutr. 2012;3:605S-610S.

10. Trevena H, Neal B, Dunford E, Wu JH. An evaluation of the effects of the australian food and health dialogue targets on the sodium content of bread, breakfast cereals and processed meats. Nutrients. 2014;6:3802-17.

11. Wyness LA, Butriss JL, Stanner SA. Reducing the population's sodium intake: the UK Food Standards Agency's salt reduction programme. Public Health Nutr. 2012;15:254-61.

12. Hendry VL, Almíron-Roig E, Monsivais P, Jebb SA, Benjamin Neelon SE, Griffin SJ, et al. Impact of regulatory interventions to reduce intake of artificial trans-fatty acids: A systematic review. Am J Public Health. 2015;105:e32-42.

13. Combris P, Goglia R, Henini M, Soler LG, Spiteri M. Improvement of the nutritional quality of foods as a public health tool. Public Health. 2011;125:717-24.

14. Bertram MY, Steyn K, Wentzel-Viljoen E, Tollman S, Hofman KJ. Reducing the sodium content of high-salt foods: Effect on cardiovascular disease in South Africa. S Afr Med J 2012;102:743.

15. Bruins MJ, Dotsch-Klerk M, Matthee J, Kearney M, van Elk K, Weber P, et al. A Modelling approach to estimate the impact of sodium reduction in soups on cardiovascular health in the netherlands. Nutrients. 2015;7:8010-9.

16. Dotsch-Klerk M, Goossens WP, Meijer GW, van het Hof KH. Reducing salt in food; setting product-specific criteria aiming at a salt intake of $5 \mathrm{~g}$ per day. Eur J Clin Nutr. 2015;69:799-804.

17. Hendriksen MA, Hoogenveen RT, Hoekstra J, Geleijnse JM, Boshuizen HC, van Raaij JM. Potential effect of salt reduction in processed foods on health. Am J Clin Nutr. 2014;99:446-53.

18. Smith-Spangler CM, Juusola JL, Enns EA, Owens DK, Garber AM. Population strategies to decrease sodium intake and the burden of cardiovascular disease: A cost-effectiveness analysis. Ann Intern Med. 2010;152:481-7.

19. Temme EHM, Millenaar IL, Van Donkersgoed G, Westenbrink S. Impact of fatty acid food reformulations on intake of Dutch young adults. Acta Cardiol. 2011;66:721-8.

20. Leroy P, Requillart V, Soler LG, Enderli G. An assessment of the potential health impacts of food reformulation. Eur J Clin Nutr. 2015;70:694-9.

21. Masset G, Mathias KC, Vlassopoulos A, Molenberg F, Lehmann U, Gibney M, et al. Modeled dietary impact of pizza reformulations in US children and adolescents. PLoS ONE. 2016;11:e0164197.

22. Roodenburg AJ, Schlatmann A, Dotsch-Klerk M, Daamen R, Dong J, Guarro M, et al. Potential effects of nutrient profiles on nutrient intakes in the Netherlands, Greece, Spain, USA, Israel, China and South-Africa. PLoS ONE. 2011;6:e14721.

23. Roodenburg AJ, van Ballegooijen AJ, Dotsch-Klerk M, van der Voet H, Seidell JC. Modelling of usual nutrient intakes: potential impact of the choices programme on nutrient intakes in young dutch adults. PLoS ONE. 2013;8:e72378.

24. van Raaij J, Hendriksen M, Verhagen H. Potential for improvement of population diet through reformulation of commonly eaten foods. Public Health Nutr. 2008;12:325-30.

25. Vlassopoulos A, Masset G, Charles VR, Hoover C, ChesneauGuillemont $\mathrm{C}$, Leroy $\mathrm{F}$ et al. A nutrient profiling system for the (re)formulation of a global food and beverage portfolio. Eur $\mathrm{J}$ Nutr. 2017;56:1105-1122.

26. Ng SW, Popkin BM. Monitoring foods and nutrients sold and consumed in the United States: dynamics and challenges. J Acad Nutr Diet. 2012;112:41.

27. Webster JL, Dunford EK, Neal BC. A systematic survey of the sodium contents of processed foods. Am J Clin Nutr. 2010;91:413-20.

28. Griffith R, O'Connell M, Smith K. The Importance of product reformulation versus consumer choice in improving diet quality. Economica. 2017;84:34-53.

29. Menard C, Dumas C, Goglia R, Spiteri M, Gillot N, Combris P, et al. OQALI: A french database on processed foods. J Food Compos Anal. 2011;24:744-9.

30. Dunford E, Webster J, Metzler AB, Czernichow S, Mhurchu CN, Wolmarans $\mathrm{P}$, et al. International collaborative project to compare and monitor the nutritional composition of processed foods. Eur $\mathbf{J}$ Prev Cardiol. 2012;19:1326-32.

31. Raghunathan R, Naylor RW, Hoyer WD. The unhealthy=tasty intuition and its effects on taste inferences, enjoyment, and choice of food products. J Mark. 2006;70:170-84. 